\title{
Structure and Thermal Stability of Copper Nitride Thin Films
}

\author{
Guangan Zhang, ${ }^{1}$ Zhibin Lu, ${ }^{1}$ Jibin Pu, ${ }^{1}$ Guizhi Wu, ${ }^{1}$ and Kaiyuan Wang ${ }^{2}$ \\ ${ }^{1}$ State Key Laboratory of Solid Lubrication, Lanzhou Institute of Chemical Physics, Chinese Academy of Sciences, \\ Lanzhou 730000, China \\ ${ }^{2}$ School of Materials Science and Engineering, East China University of Science and Technology, Shanghai 200237, China \\ Correspondence should be addressed to Guangan Zhang; gazhang@licp.cas.cn
}

Received 26 June 2013; Accepted 4 August 2013

Academic Editors: Y. Habibi and A. Sotelo

Copyright (c) 2013 Guangan Zhang et al. This is an open access article distributed under the Creative Commons Attribution License, which permits unrestricted use, distribution, and reproduction in any medium, provided the original work is properly cited.

Copper nitride $\left(\mathrm{Cu}_{3} \mathrm{~N}\right)$ thin films were deposited on glass via DC reactive magnetron sputtering at various $\mathrm{N}_{2}$ flow rates and partial pressures with $150^{\circ} \mathrm{C}$ substrate temperature. X-ray diffraction and scanning electron microscopy were used to characterize the microstructure and morphology. The results show that the films are composed of $\mathrm{Cu}_{3} \mathrm{~N}$ crystallites with anti- $\mathrm{ReO}_{3}$ structure. The microstructure and morphology of the $\mathrm{Cu}_{3} \mathrm{~N}$ film strongly depend on the $\mathrm{N}_{2}$ flow rate and partial pressure. The cross-sectional micrograph of the film shows typical columnar, compact structure. The thermal stabilities of the films were investigated using vacuum annealing under different temperature. The results show that the introducing of argon in the sputtering process decreases the thermal stability of the films.

\section{Introduction}

Transition metal nitrides show a wide variety of properties and have lots of applications, and some of them have acquired a large number of industrial application. Among them, copper nitrides have attracted considerable attention as a new material for optical storage devices and high speed integrated circuits, based on its unique properties, such as rather low thermal decomposition temperature, excellent electrical properties, and optical qualities [1,2]. All of these properties are due to its special cubic anti- $\mathrm{ReO}_{3}$ structure. A number of nonequilibrium techniques, such as RF reactive sputtering [1,3-7], DC magnetron sputtering [8], ion assisted vapor deposition [9], reactive pulsed laser deposition [10], and other methods [11], are currently used for the preparation of $\mathrm{Cu}_{3} \mathrm{~N}$ films. In recent years, Terada et al. [3] prepared oriented epitaxial films by the reactive rf magnetron sputtering method on the $\mathrm{Pt} / \mathrm{MgO}$ and $\mathrm{Al}_{2} \mathrm{O}_{3}$ substrates. They also reported that copper nitride films were amorphous on glass, $\mathrm{MgO}$, and $\mathrm{SrTiO}_{3}$ substrates. Maruyama and Morishita [12] have studied the electrical and optical characteristics of the films prepared by $\mathrm{rf}$ reactive sputtering. And the electrical and optical properties of the copper nitride films critically depended on the sputter process parameters such as nitrogen partial pressure, sputtering pressure, substrate temperature, and substrate bias voltage. The electrical resistivity of the films varied from $2 \times 10^{-3} \Omega \mathrm{cm}$ to about $10^{3} \Omega \mathrm{cm}$, and the optical band gap of the films increased from $0.8 \mathrm{eV}$ to $1.9 \mathrm{eV}$ with the various sputtering process parameters [12-15]. Liu et al. [5] and Ji et al. [16] have studied thermal stability of the films. Yue et al. $[1,17]$ have studied the structure, thermal properties, optical properties, and Hall effects of the $\mathrm{Cu}_{3} \mathrm{~N}$ films. The mechanical properties of the copper nitride films were also studied by Pierson $[4,14,15]$. However, the structure and thermal properties of the films, which may influence significantly on the applications of electronic and optical storage, were found to be dependent on substrate, growth technologies, and preparation process.

However, the influence of the formation process on the structure, morphology, and thermal properties of copper nitride is still not very clear. It was therefore decided to study the formation and stability of copper nitride films. In preparation of the films, the DC magnetron sputtering method was used in which the influences of $\mathrm{N}_{2}$ flow rate and $\mathrm{N}_{2}$ partial pressure on the copper nitride films prepared at $150^{\circ} \mathrm{C}$ substrate temperature were investigated systematically. In a thermal stability study, the vacuum annealing process was used, with our objective being to describe the decomposition 


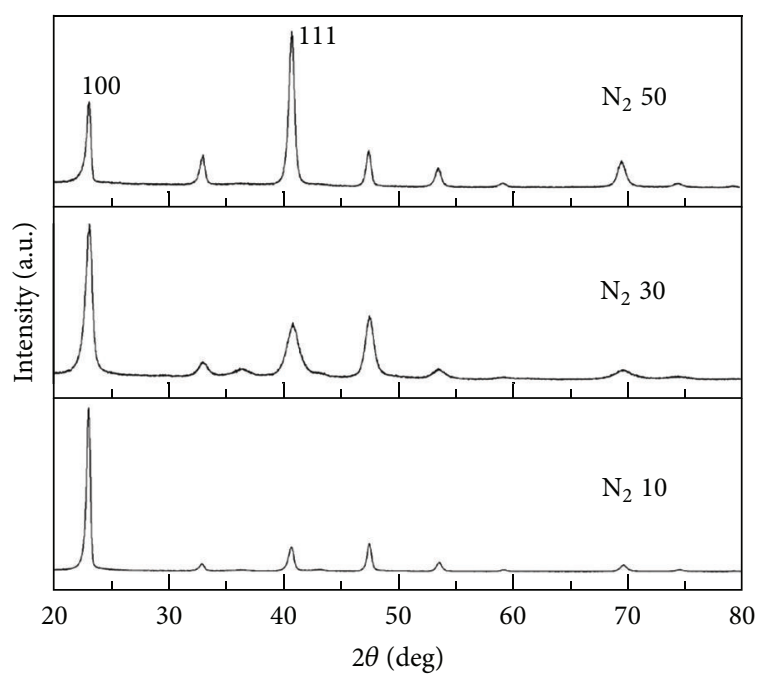

FIGURE 1: The X-ray diffraction spectra of $\mathrm{Cu}_{3} \mathrm{~N}$ films with different $\mathrm{N}_{2}$ flow rates.

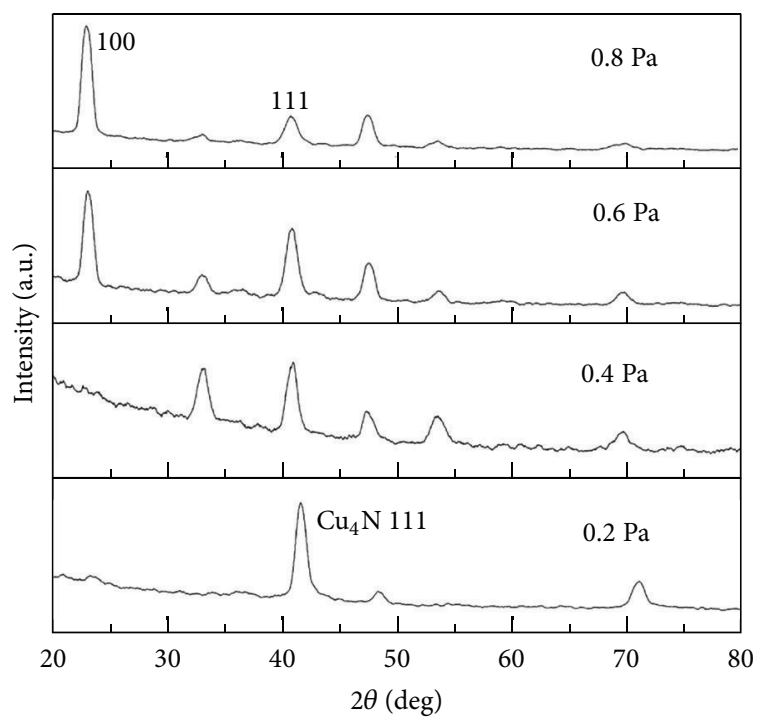

Figure 2: The X-ray diffraction spectra of $\mathrm{Cu}_{3} \mathrm{~N}$ films with different $\mathrm{N}_{2}$ partial pressure.

process of the films in detail so that a critical decomposition temperature could be found.

\section{Experiment}

Thin copper nitride films were prepared with a DC reactive magnetron sputtering with a columnar target (99.99\% pure copper) on glass. The experimental equipment has been described in detail elsewhere [18], so only a brief description of experiment is given here. The glass wafers were ultrasonically cleaned in acetone and methanol and finally dried with blowing gas. The substrate was placed parallel to the target at $150 \mathrm{~mm}$. Before sputtering, the chamber was evacuated to less than $1.0 \times 10^{-3} \mathrm{~Pa}$. The working gas (99.999\% pure argon and $99.999 \%$ pure nitrogen) was introduced to the chamber.
The Ar and $\mathrm{N}_{2}$ gas flow rate were adjusted by independent mass-flow controllers. The partial pressures of $\mathrm{Ar}$ and $\mathrm{N}_{2}$ in the chamber were estimated by their respective flow rates measured by the mass-flow controllers. The total sputtering pressure was maintained at $1 \mathrm{~Pa}$ by controlling the pumping rates during the sputtering. The substrate temperature during the sputtering maintained at $150^{\circ} \mathrm{C}$. The power applied to the target is fixed at $1000 \mathrm{~W}$ throughout the study.

The film thickness was determined using a long scan profiler (2206, Harbin, China). The crystalline structures of the films were identified with an X-ray diffractometer (D/Max-2400X, Rigaku Co., Japan) using $\mathrm{Cu} \mathrm{K}_{\alpha}$ radiation. Scanning electron microscopy (JSM-5600LV, Electron Optical Co., Japan) and atomic force microscopy (SPM-9500, Shimadzu, Japan) were performed to investigate the state of the surface and the cross-section of the specimens and to search for characters that have occurred in the deposited films. In order to study the thermal stability of $\mathrm{Cu}_{3} \mathrm{~N}$ thin films, the as-deposited samples were annealed in vacuum (pressure $=3.0 \times 10^{-3} \mathrm{~Pa}$ ) for $1 \mathrm{~h}$ at a temperature ranging from $150^{\circ} \mathrm{C}$ to $300^{\circ} \mathrm{C}$. Then the samples were cooled to room temperature under same vacuum conditions.

\section{Results and Discussion}

3.1. Film Deposition and Structure. The deposition rate was estimated from the film thickness and the corresponding deposition time. The deposition rate of the mixture $\mathrm{N}_{2}$ $30 \mathrm{sccm} /$ Ar $20 \mathrm{sccm}$ was $66.7 \mathrm{~nm} /$ minute, while for pure $\mathrm{N}_{2}$ $30 \mathrm{sccm}$ flow rate was only $38.3 \mathrm{~nm} /$ minute. The deposition rates of the films decrease dramatically in a pure reactive $\mathrm{N}_{2}$ atmosphere. This is partly due to the poor sputtering capability of nitrogen compared to argon and partly from the target poisoning effects (induced by the reactive $\mathrm{N}_{2}$ atmosphere) where the sputtering yield for nitride is much smaller than the metal, and partly due to that these compounds have higher secondary electron emission yields than metal targets [19]. The additional Ar can dramatically increase the sputtering of $\mathrm{Cu}$ and $\mathrm{Cu}_{3} \mathrm{~N}$ and have a negative influence of forming nitride compound layer on the target surface and consequently results in a large increase of the deposition rate.

Figure 1 shows the X-ray diffraction (XRD) spectra of $\mathrm{Cu}_{3} \mathrm{~N}$ films prepared on glass at different $\mathrm{N}_{2}$ flow rates of 50 , 30 , and $10 \mathrm{sccm}$ with pressure of $1 \mathrm{~Pa}$. The XRD spectra are corresponding to the cubic anti- $\mathrm{ReO}_{3}$ structure of $\mathrm{Cu}_{3} \mathrm{~N}$, and no $\mathrm{Cu}$ peaks are found in all the films. The films formed under $50 \mathrm{sccm} \mathrm{N} \mathrm{N}_{2}$ flow rates had grown with an obviously preferred orientation of [111]. The preferred growth orientation of the film changed gradually to [100] as $\mathrm{N}_{2}$ flow rates decreased to $30 \mathrm{sccm}$, and the diffraction peaks of (111) and (200) are also very strong. The XRD spectra of the films deposited at $\mathrm{N}_{2}$ flow rate of $10 \mathrm{sccm}$ are preferred to [100] orientation and almost the same as the films deposited at $30 \mathrm{sccm} \mathrm{N}$ flow rate. However, the (111) diffraction peak of the films that deposited $\mathrm{N}_{2}$ flow rates is even weaker than that of films deposited at $30 \mathrm{sccm} \mathrm{N} \mathrm{N}_{2}$ flow rate.

Figure 2 shows the XRD spectra of the films prepared at different $\mathrm{N}_{2}$ partial pressure with total pressure of $\mathrm{N}_{2}$ and Ar gas mixture maintained at $1 \mathrm{~Pa}$. The sputtering lasted for 


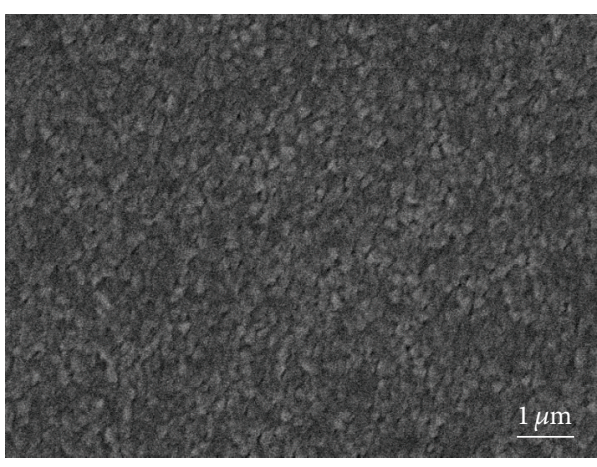

(a)

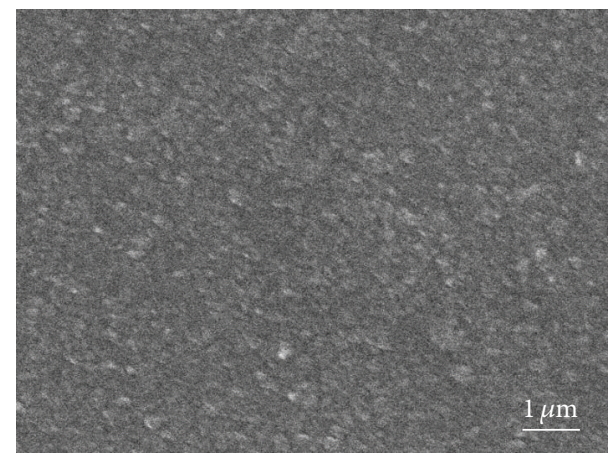

(b)

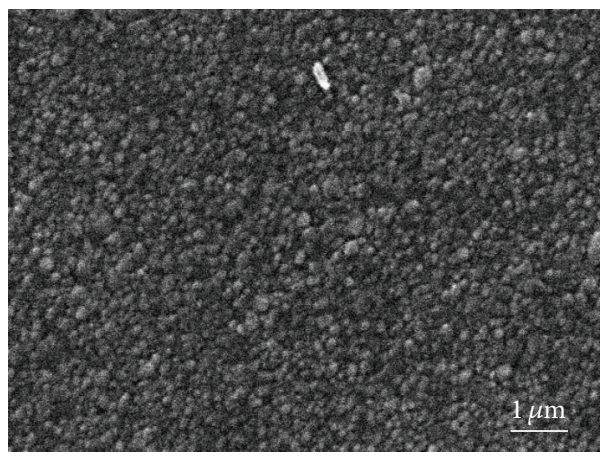

(c)

FIgure 3: The SEM image of $\mathrm{Cu}_{3} \mathrm{~N}$ film deposited under various $\mathrm{N}_{2}$ flow rate $50 \mathrm{sccm} ; 30 \mathrm{sccm} ; 10 \mathrm{sccm}$.

$20 \mathrm{~min}$. The XRD spectra of the films prepared at $0.8 \mathrm{~Pa} \mathrm{~N}_{2}$ partial pressure show a strong [100] orientation. The XRD spectra also show that the films prefer [100] orientation, but the (111) and (200) peaks become stronger at the $\mathrm{N}_{2}$ partial pressure of $0.6 \mathrm{~Pa}$. For the films prepared at $0.4 \mathrm{~Pa} \mathrm{~N}_{2}$ partial pressure, the [100] peaks disappeared. For the films prepared at $0.2 \mathrm{~Pa} \mathrm{~N}_{2}$ partial pressure, the $\mathrm{Cu}_{4} \mathrm{~N}$ (111) peaks were observed $[12,20]$. The preferred orientation of the as-deposited copper nitride films is interpreted to depend mainly on the mobility of the $\mathrm{Cu}$ and $\mathrm{N}$ atoms participating in the film growth process [2]. Such mobility is expected to be a function of the ratio between the number of $\mathrm{N}$ and $\mathrm{Cu}$ atoms reaching the substrate and also of the kinetic energies of these atoms. The preferred orientation transformed from $\mathrm{Cu}$-rich orientation [111] to N-rich orientation [100] as $\mathrm{N}_{2}$ partial pressure increased, which indicates that large amount of $\mathrm{Cu}$ and $\mathrm{N}$ atoms formed $\mathrm{N}$-rich orientation at higher $\mathrm{N}_{2}$ partial pressure.

3.2. Morphology. Figure 3 shows the surface morphology of the $\mathrm{Cu}_{3} \mathrm{~N}$ films deposited at different $\mathrm{N}_{2}$ flow rates. It is obvious that all the films are extremely smooth, compact, and uniform. It can be found that the $\mathrm{N}_{2}$ flow rates had no significant influence on the grain size of the $\mathrm{Cu}_{3} \mathrm{~N}$ films; however, the grain shapes were influenced obviously. Pyramid cone structure was found in $\mathrm{Cu}_{3} \mathrm{~N}$ films and deposited at $50 \mathrm{sccm} \mathrm{N}_{2}$ flow rate (Figure 3(a)). Figure 3(b) is also the pyramid cone morphology of $\mathrm{Cu}_{3} \mathrm{~N}$ film deposited at $30 \mathrm{sccm} \mathrm{N} N_{2}$ flow rate. For the $\mathrm{N}_{2}$ flow rate of $10 \mathrm{sccm}$
(Figure 3(c)), grains on the surface appeared obviously as uniformly nodular-like morphology.

The topography shown in Figure 4 suggests that the film is prepared with mixture of $\mathrm{N}_{2}$ and Ar. The grain size of the films increases with the argon introduced in the reactive atmosphere. The copper nitride films prepared at $0.8 \mathrm{~Pa} \mathrm{~N}_{2}$ partial pressure also show pyramid cone morphology (Figure 4(a)). However, the film prepared at $0.6 \mathrm{~Pa} \mathrm{~N}_{2}$ partial pressure is composed of large polygonal grains (of up to micrometer scale) with irregular tops separated by a large number of porous boundaries (Figure 4(b)). The additional Ar gas can dramatically increase the deposition rate of the films, and high deposition rate may cause larger grain size and sharp grain boundaries.

Difference in crystallite orientation and deposition rate of adatoms is believed to be responsible for the great changes in morphology. For the $\mathrm{Cu}_{3} \mathrm{~N}$ films prepared at $\mathrm{N}_{2}$ flow rate of $10 \mathrm{sccm}$, the crystallite orientation [100] is much stronger, while other orientations are very weak. This fine [100] preferred orientation caused nodular-like morphology as a result of isotropic growth. While at higher $\mathrm{N}_{2}$ flow rate and the argon introduction the pyramid cone morphology appeared. This phenomenon can be attributed to the multiplicate crystallite orientation. In the deposition process, [111] and [100] orientation had a competitive growth and thus presented complicated pyramid cone morphology.

In order to understand more details of the grains, we use atomic force microscopy images. Figure 5 shows the image of film deposited under $\mathrm{N}_{2}$ flow rate of $50 \mathrm{sccm}$. We can clearly 


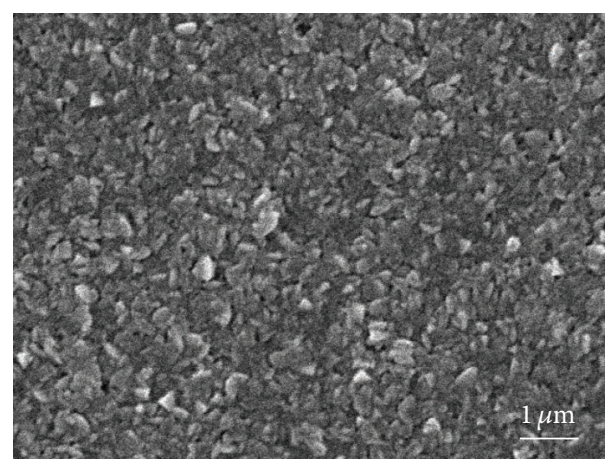

(a)

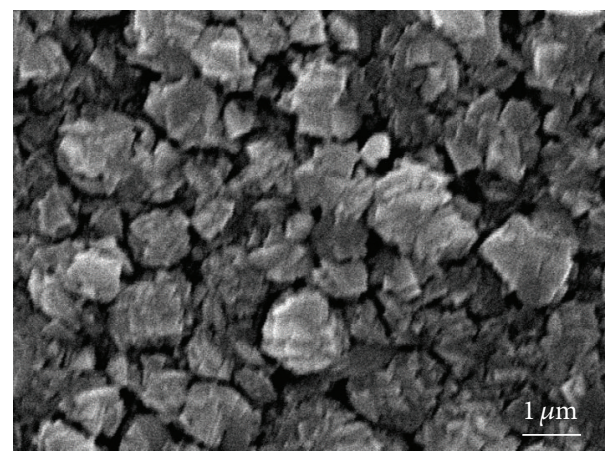

(b)

FIgURE 4: The SEM image of $\mathrm{Cu}_{3} \mathrm{~N}$ film deposited under various $\mathrm{N}_{2}$ partial pressure $0.8 \mathrm{~Pa} ; 0.6 \mathrm{~Pa}$.

see that several small grains of size $\sim 50 \mathrm{~nm}$ agglomerated together and formed a big grain boundary (grains as seen in SEM images).

A typical cross-sectional micrograph is also shown in Figure 6, where the formation of columnar grains perpendicular to the substrate surface and a smooth film surface morphology is clearly shown. It is known that the columnar structure formed due to the high deposition rate and low lateral adatoms mobility. The columnar boundary is due to an accumulation effect of the crystallographic flaws that are built into the thin films during deposition and then enriched in the boundary.

3.3. Thermal Stability. The $\mathrm{Cu}_{3} \mathrm{~N}$ films deposited at $\mathrm{N}_{2}$ flow rate of $10 \mathrm{sccm}$ and $\mathrm{N}_{2}$ partial pressure of $0.8 \mathrm{~Pa}$ were annealed in vacuum (pressure $=3.0 \times 10^{-3} \mathrm{~Pa}$ ) for $1 \mathrm{~h}$ at a temperature ranging from $150^{\circ} \mathrm{C}$ to $300^{\circ} \mathrm{C}$. Figures 7 and 8 show the XRD spectra of the heat treated $\mathrm{Cu}_{3} \mathrm{~N}$ films compared with as prepared films. For the film prepared at pure nitrogen atmosphere (Figure 7), it is found that as the heating temperature at $150^{\circ} \mathrm{C}$, the intensity of $\mathrm{Cu}_{3} \mathrm{~N}$ (111) and (200) diffraction peaks decreased and almost disappeared, and when the heating temperature reached $200^{\circ} \mathrm{C}$ and $250^{\circ} \mathrm{C}$, the diffraction peaks did not show obviously changes. Further increase the heating temperature to $300^{\circ} \mathrm{C}$, the $\mathrm{Cu}$ (111) peaks appeared, which indicated that decomposition took place at the temperature ranges from $250^{\circ} \mathrm{C}$ to $300^{\circ} \mathrm{C}$, lower than the decomposition temperature (about $360^{\circ} \mathrm{C}$ ) [6]. However, the

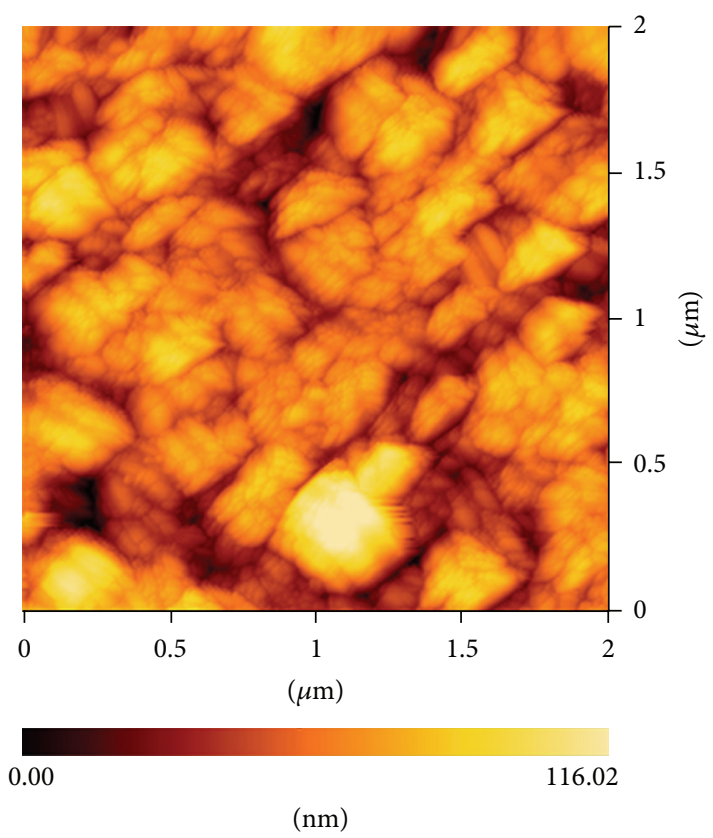

(a)

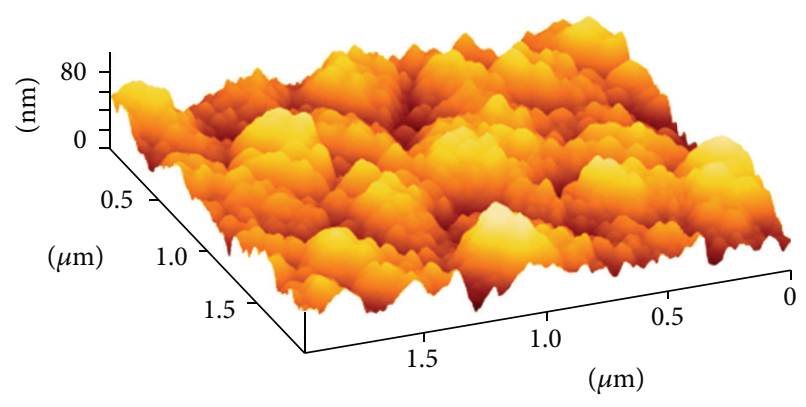

(b)

FIgURE 5: The AFM image of $\mathrm{Cu}_{3} \mathrm{~N}$ film deposited under $\mathrm{N}_{2}$ flow rate of $50 \mathrm{sccm}$.

evolution of the phase structure and decomposition temperature of the film deposited at mixed $\mathrm{N}_{2}$ and Ar atmosphere is unlike the film deposited at pure $\mathrm{N}_{2}$ atmosphere (Figure 8). When the heating temperature at $150^{\circ} \mathrm{C}$, the intensity of $\mathrm{Cu}_{3} \mathrm{~N}$ (111) diffraction peaks increased and the intensity closed to that of (100). At $200^{\circ} \mathrm{C}$ heating temperature, the intensity of (100) peaks is stronger than the (111) peaks. However, at $250^{\circ} \mathrm{C}$ heating temperature, $\mathrm{Cu}$ peaks appeared without obvious $\mathrm{Cu}_{3} \mathrm{~N}$ peaks. This indicates that $\mathrm{Cu}_{3} \mathrm{~N}$ phase has been transformed into $\mathrm{Cu}$ phase completely through annealing treatment at a temperature of $250^{\circ} \mathrm{C}$. The color change of $\mathrm{Cu}_{3} \mathrm{~N}$ films also can provide information of phase transform. The decomposition temperature of $\mathrm{Cu}_{3} \mathrm{~N}$ in our experiment is higher than $\mathrm{Cu}_{3} \mathrm{~N}$ annealing in vaccum as reported [5].

One possibility of this difference of decomposition temperature is the structure. The films prepared at pure nitrogen atmosphere show a small particle size with a relative compact texture, while the films prepared at mixed nitrogen and argon atmosphere show a larger particle size with obvious large number of void boundaries with a looser texture. And the 


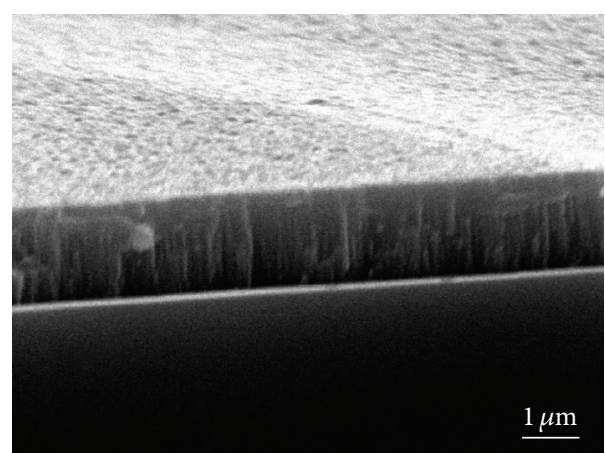

FIGURE 6: The typical cross-sectional SEM image of $\mathrm{Cu}_{3} \mathrm{~N}$ film.

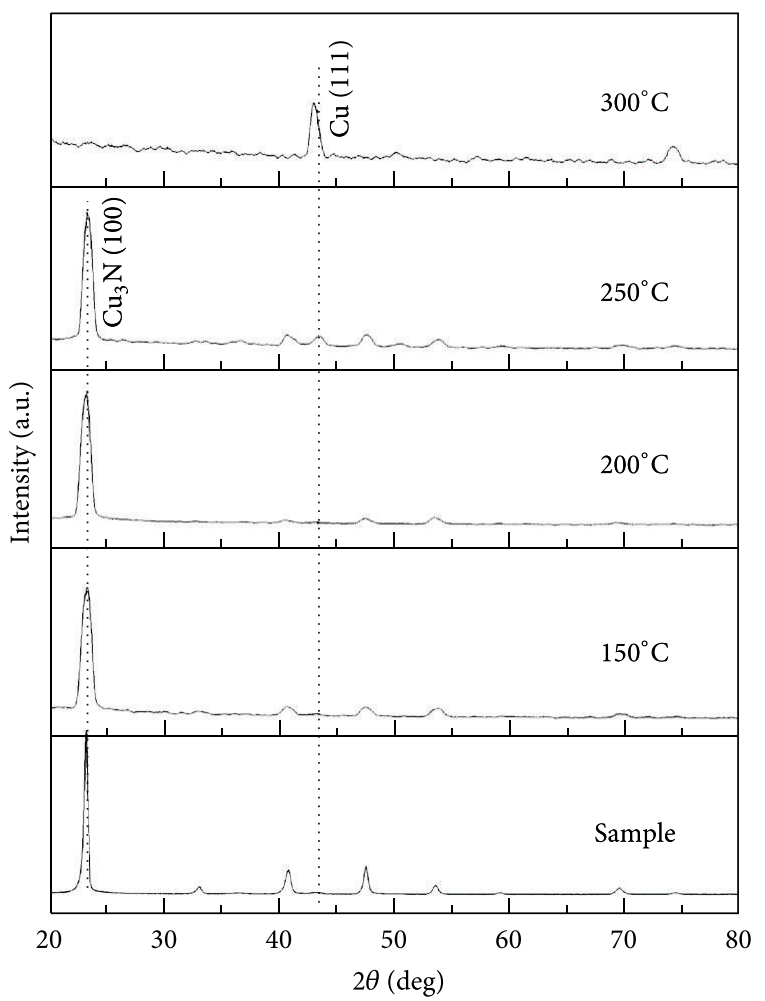

Figure 7: The X-ray diffraction spectra of $\mathrm{Cu}_{3} \mathrm{~N}$ films prepared with pure $\mathrm{N}_{2}$ atmosphere annealing at different annealing temperature.

decomposition process may begin at these void boundaries. Finally, the film shows a lower decomposition temperature.

\section{Conclusion}

Copper nitride $\left(\mathrm{Cu}_{3} \mathrm{~N}\right)$ thin films were deposited on glass via DC reactive magnetron sputtering at various $\mathrm{N}_{2}$ flow rates and partial pressures with $150^{\circ} \mathrm{C}$ substrate temperature. $\mathrm{X}$-ray diffraction measurements show that the films are composed of $\mathrm{Cu}_{3} \mathrm{~N}$ crystallites with anti- $\mathrm{ReO}_{3}$ structure. The preferred growth orientation of the film turned from [111] to [100] as $\mathrm{N}_{2}$ flow rates decrease. And the preferred orientation also transformed from orientation [111] to [100] as $\mathrm{N}_{2}$ partial pressure increased. The $\mathrm{N}_{2}$ flow rates had no

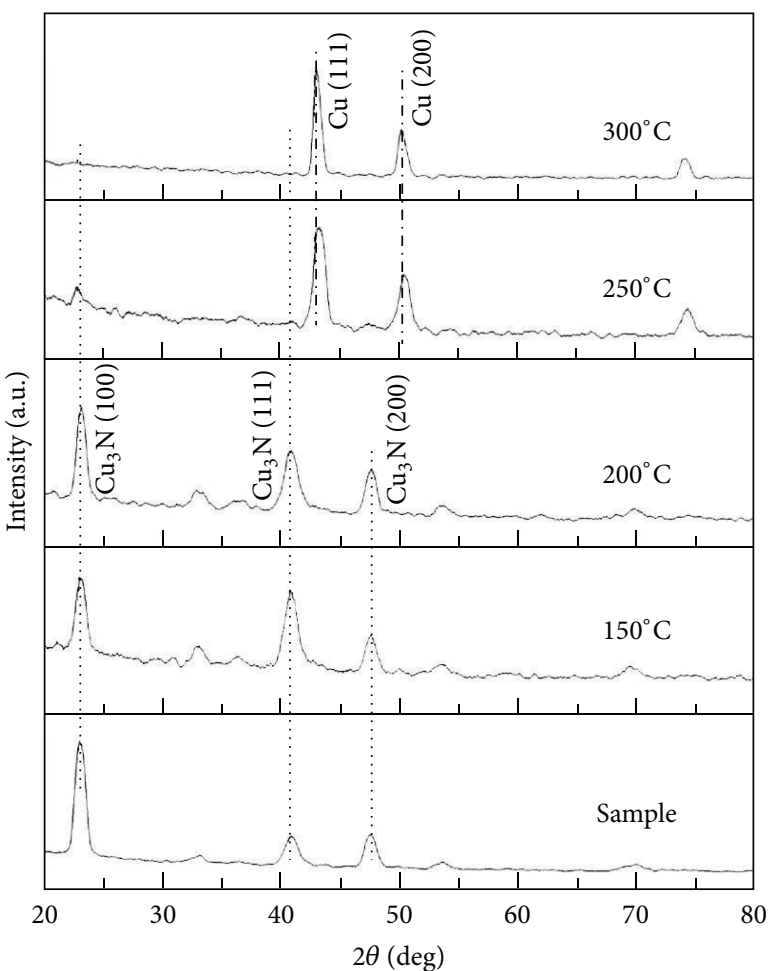

FIGURE 8: The X-ray diffraction spectra of $\mathrm{Cu}_{3} \mathrm{~N}$ films prepared with $\mathrm{N}_{2}$ and Ar mixture atmosphere annealing at different annealing temperature.

significant influence on the grain size of the $\mathrm{Cu}_{3} \mathrm{~N}$ films except the grain shapes. For a lower $\mathrm{N}_{2}$ flow rates, grains on the surface appeared obviously as uniform nodular-like morphology. While the high $\mathrm{N}_{2}$ flow rates and the addition of the Ar, grains presented pyramid cone morphology due to multiple growth orientations. The cross-sectional micrograph of the film shows typical columnar, compact structure. The decomposition temperature of the mixed argon and nitrogen atmosphere is lower than the film prepared at pure nitrogen atmosphere. The results show that the introducing of argon in the sputtering process decreases the thermal stability properties due to its looser texture.

\section{References}

[1] G. H. Yue, P. X. Yan, J. Z. Liu, M. X. Wang, M. Li, and X. M. Yuan, "Copper nitride thin film prepared by reactive radio-frequency magnetron sputtering," Journal of Applied Physics, vol. 98, Article ID 103506, 2005.

[2] K. J. Kim, J. H. Kim, and J. H. Kang, "Structural and optical characterization of $\mathrm{Cu}_{3} \mathrm{~N}$ films prepared by reactive $\mathrm{RF}$ magnetron sputtering," Journal of Crystal Growth, vol. 222, no. 4, pp. 767$772,2001$.

[3] S. Terada, H. Tanaka, and K. Kubota, "Heteroepitaxial growth of $\mathrm{Cu}_{3} \mathrm{~N}$ thin films," Journal of Crystal Growth, vol. 94, no. 2, pp. $567-568,1989$.

[4] J. F. Pierson, "Structure and properties of copper nitride films formed by reactive magnetron sputtering," Vacuum, vol. 66, no. 1, pp. 59-64, 2002. 
[5] Z. Q. Liu, W. J. Wang, T. M. Wang, S. Chao, and S. K. Zheng, "Thermal stability of copper nitride films prepared by rf magnetron sputtering," Thin Solid Films, vol. 325, no. 1-2, pp. 55-59, 1998.

[6] T. Nosaka, M. Yoshitake, A. Okamoto, S. Ogawa, and Y. Nakayama, "Thermal decomposition of copper nitride thin films and dots formation by electron beam writing," Applied Surface Science, vol. 169-170, pp. 358-361, 2001.

[7] J. Wang, J. T. Chen, X. M. Yuan, Z. G. Wu, B. B. Miao, and P. $X$. Yan, "Copper nitride $\left(\mathrm{Cu}_{3} \mathrm{~N}\right)$ thin films deposited by $\mathrm{RF}$ magnetron sputtering," Journal of Crystal Growth, vol. 286, no. 2, pp. 407-412, 2006.

[8] L. Maya, "Deposition of crystalline binary nitride films of tin, copper, and nickel by reactive sputtering," Journal of Vacuum Science and Technology A, vol. 11, p. 604, 1993.

[9] M. Asano, K. Umeda, and A. Tasaki, " $\mathrm{Cu}_{3} \mathrm{~N}$ thin film for a new light recording media," Japanese Journal of Applied Physics, vol. 29, pp. 1985-1986, 1990.

[10] G. Soto, J. A. Díaz, and W. de la Cruz, "Copper nitride films produced by reactive pulsed laser deposition," Materials Letters, vol. 57, no. 26-27, pp. 4130-4133, 2003.

[11] M. Sicha, Z. Hubicka, L. Soukup, L. Jastrabık, M. Cada, and P. Spatenka, "Low-pressure RF multi-plasma-jet system for deposition of alloy and composite thin films," Surface and Coatings Technology, vol. 148, no. 2-3, pp. 199-205, 2001.

[12] T. Maruyama and T. Morishita, "Copper nitride thin films prepared by radio-frequency reactive sputtering," Journal of Applied Physics, vol. 78, p. 4104, 1995.

[13] Z. Liu, X. Li, A. Zuo, Z. Yuan, J. Yang, and K. Yao, "Effect of $\mathrm{N}_{2}$ gas partial pressure on the structure and properties of copper nitride films by DC reactive magnetron sputtering," Plasma Science and Technology, vol. 9, no. 2, article 147, 2007.

[14] K. Venkata Subba Reddy, A. Sivasankar Reddy, P. Sreedhara Reddy, and S. Uthanna, "Copper nitride films deposited by dc reactive magnetron sputtering," Journal of Materials Science, vol. 18, no. 10, pp. 1003-1008, 2007.

[15] K. V. S. Reddy, T. K. Subramanyam, and S. Uthanna, "Nitrogen partial pressure influence on physical properties of DC magnetron sputtered copper nitride films," Optoelectronics and Advanced Materials, vol. 1, pp. 31-35, 2007.

[16] Z. Ji, Y. Zhang, Y. Yuan, and C. Wang, "Reactive DC magnetron deposition of copper nitride films for write-once optical recording," Materials Letters, vol. 60, no. 29-30, pp. 3758-3760, 2006.

[17] G. H. Yue, J. Z. Liu, M. Li, X. M. Yuan, P. X. Yan, and J. L. Liu, "Hall effect of copper nitride thin films," Physica Status Solidi (a), vol. 202, no. 10, pp. 1987-1993, 2005.

[18] Z. G. Wu, W. W. Zhang, L. F. Bai, J. Wang, and P. X. Yan, "Preparation and properties of nano-structure $\mathrm{Cu}_{3} \mathrm{~N}$ thin films," Acta Physica Sinica, vol. 54, pp. 1689-1692, 2005 (Chinese).

[19] Z. Han, J. Tian, Q. Lai, X. Yu, and G. Li, "Effect of $\mathrm{N}_{2}$ partial pressure on the microstructure and mechanical properties of magnetron sputtered $\mathrm{CrN}_{x}$ films," Surface and Coatings Technology, vol. 162, no. 2-3, pp. 189-193, 2003.

[20] J. Blucher and K. Bang, "Preparation of the metastable interstitial copper nitride, $\mathrm{Cu}_{4} \mathrm{~N}$, by d.c. plasma ion nitriding," Materials Science and Engineering A, vol. 117, pp. L1-L3, 1989. 

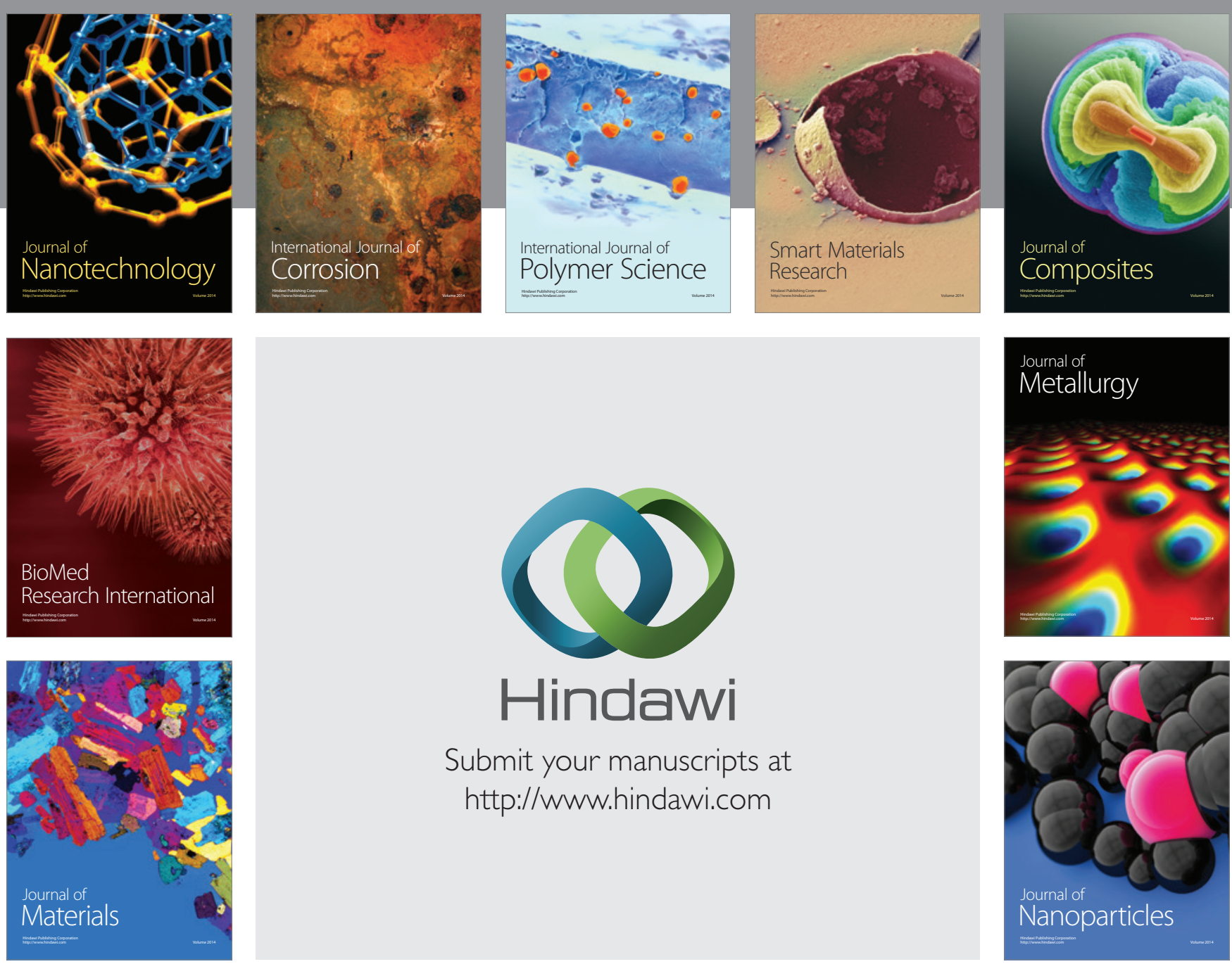

Submit your manuscripts at http://www.hindawi.com
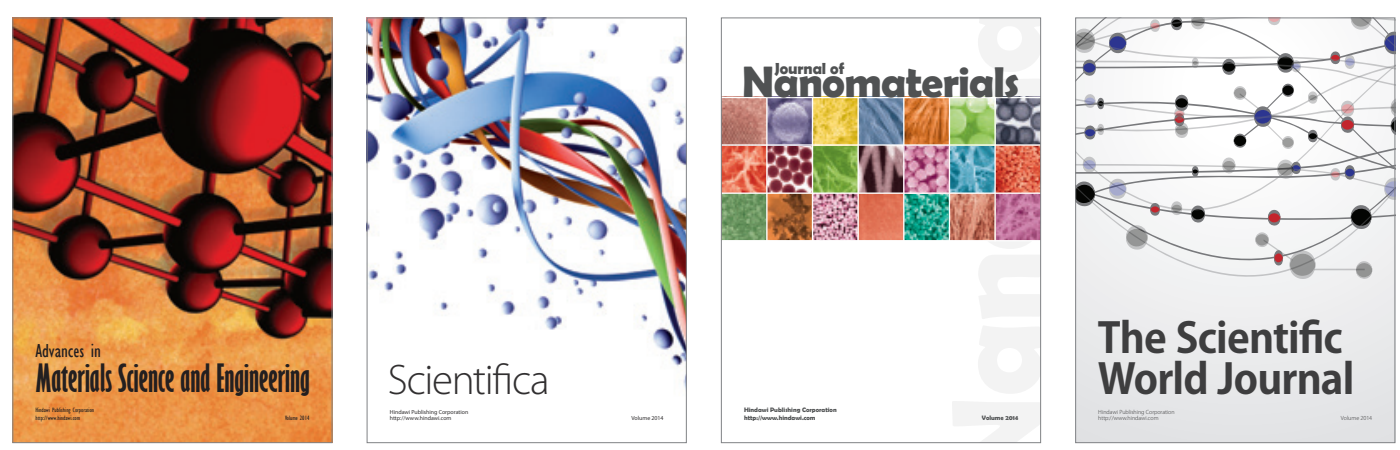

\section{The Scientific World Journal}
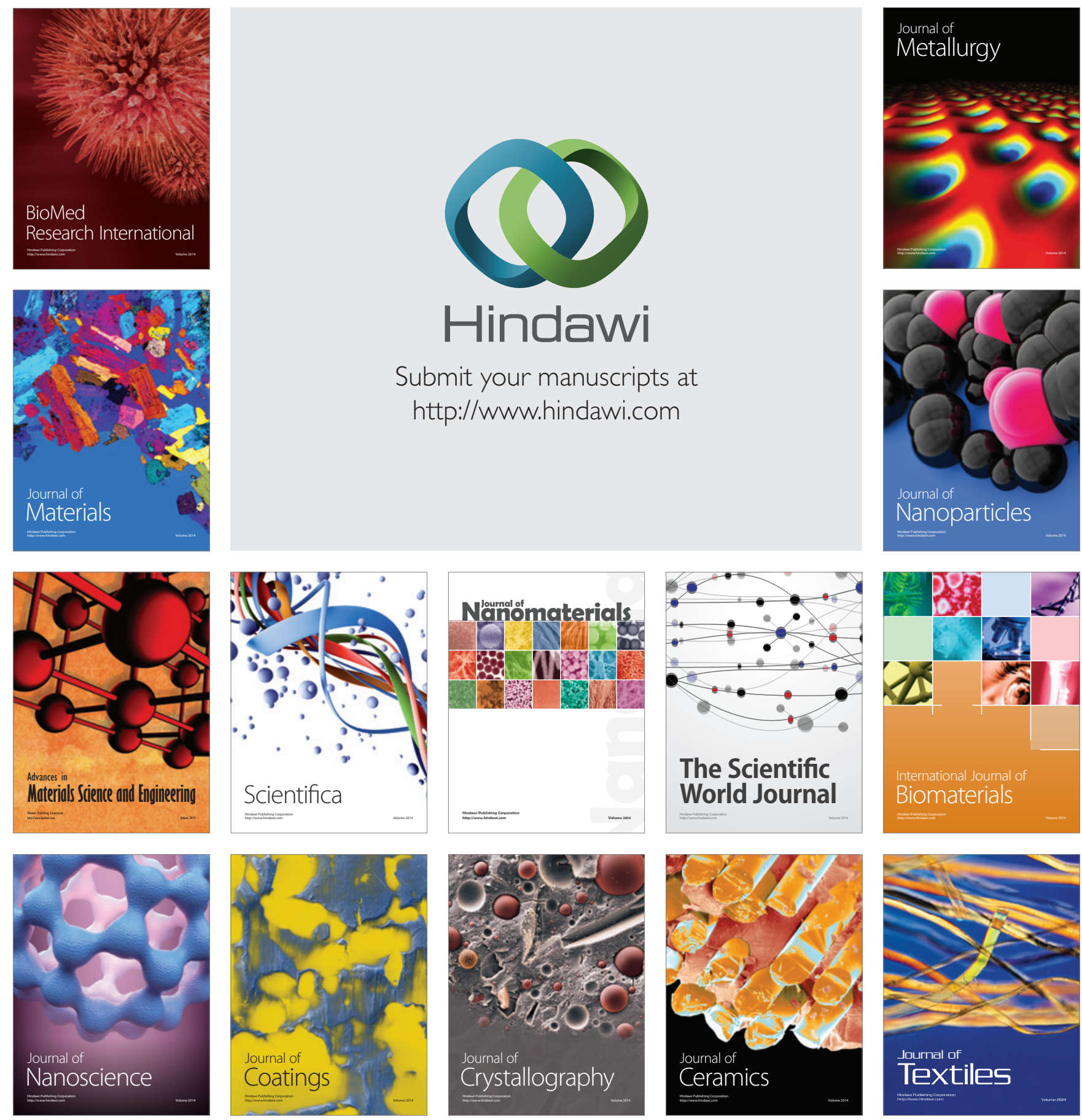